\title{
A comparison of non-viral vectors for gene delivery to pancreatic B-cells: Delivering a hypoxia-inducible vascular endothelial growth factor gene to rat islets
}

\author{
BYUNG-WAN LEE ${ }^{1}$, HEE-YOUNG CHAE ${ }^{1}$, TRAN THI NGOC TUYEN ${ }^{2}$, \\ DONGCHUL KANG ${ }^{2}$, HYUN AH KIM ${ }^{3}$, MINHYUNG LEE ${ }^{3}$ and SUNG HEE IHM ${ }^{1}$
}

${ }^{1}$ Department of Internal Medicine, Hallym University College of Medicine, Chuncheon; ${ }^{2}$ Ilsong Institute of Life Science, Hallym University, Anyang; ${ }^{3}$ Department of Bioengineering, College of Engineering, Hanyang University, Seoul, Korea

Received January 19, 2009; Accepted March 24, 2009

DOI: 10.3892/ijmm_00000189

\begin{abstract}
Although non-viral vectors are relatively safe, they have very low gene transfection efficiency, especially in pancreatic islet cells. To provide information on the use of nonviral vectors for transfecting genes into pancreatic islet cells, a comparative evaluation of non-viral options was performed. In vitro experiments were used to compare the transfection efficiency of three classes of non-viral vectors: Effectene, polyethylenimine (PEI, $25 \mathrm{kDa}$ ) and hemagglutinating virus of Japan-envelope (HVJ-E), into insulinoma cells (INS-1) and rat islets. Vascular endothelial growth factor (VEGF) gene with hypoxia-inducible RTP801 promoter was delivered into rat islets with Effectene and VEGF secretion under hypoxia was measured in the culture media. Luciferase activity and GFP assays indicated that Effectene exhibited the highest transfection efficiency, and HVJ-E was not suitable for transfection into pancreatic $\beta$-cells. The cytotoxicity of Effectene was found to be similar to that of 25-kDa PEI by 7-amino actinomycin D (7-AAD) flow cytometry and acridine orange/ propidium iodide (AO/PI) assays. When RTP801 promoterVEGF plasmid was delivered to rat islets with Effectene, VEGF secretion increased specifically in islets under hypoxia. In conclusion, Effectene showed higher gene-delivery efficiency for pancreatic islets compared with other classes of non-viral delivery systems and is promising as a gene delivery agent for pretransplant ex vivo gene therapy of islets.
\end{abstract}

Correspondence to: Dr Minhyung Lee, Department of Bioengineering, Hanyang University, 17 Haengdang-dong, Seongdong-gu, Seoul 133-791, Korea

E-mail: minhyung@hanyang.ac.kr

Dr Sung Hee Ihm, Department of Internal Medicine, Hallym University Sacred Heart Hospital, 896 Pyungchon-dong, Dongan-gu, Anyang, Kyonggi-do, 431-070, Korea

E-mail: ihmsh@hallym.ac.kr

Key words: non-viral vector, Effectene, vascular endothelial growth factor, islets

\section{Introduction}

Islet transplantation is a promising therapeutic intervention for type 1 diabetes mellitus. One of the significant obstacles to successful pancreatic islet transplantation is the high number of non-functioning islet grafts during the first few days after implantation (1). Moreover, a significant proportion of the functioning islet grafts is gradually destroyed, presumably due to ischemic damage, instant blood-mediated inflammatory reaction (IBMIR), non-specific injuries or immune destruction $(2,3)$. To overcome these obstacles and improve the outcome of islet transplantation, genetic modification of islets was attempted (4). The choice of non-viral and viral gene delivery vectors for ex vivo gene therapy of islets prior to transplantation depends on the desired level and duration of gene expression (5). Although non-viral vectors are relatively safe, they have very low transfection efficiency. Depending on the target gene, however, transient gene expression in a small portion of islet cells may be sufficient $(1,4,6)$.

The majority of the non-viral vectors used for gene therapy, such as non-lipid cationic polymers [polyethylenimine (PEI), polyamidoamine (PAMAM), poly-L-lysine], hemagglutinating virus of Japan-envelope (HVJ-E, an inactivated Sendai virus envelope), cationic liposomal lipid (Lipofectamine), and cationic non-liposomal lipids (Effectene), were developed for favorable transfection efficiency in gene transfer (7-9). To our knowledge, there are very few reports on introducing foreign DNA into islets using non-viral delivery vectors $(4,6,10,11)$.

We used a comparative approach to analyze the transfection efficiency and cytotoxicity of three classes of non-viral vectors; Effectene, PEI (25 kDa) and HVJ-E, in dividing rat insulinoma cells (INS-1) and non-dividing rat islet cells to provide information on their potential for transfecting human islet cells in vitro, and their possible applicability for human islets in vivo.

\section{Materials and methods}

Cell culture and islet isolation. INS-1 rat insulinoma cells were cultured in RPMI-1640 (11 mM glucose, $1 \mathrm{mM}$ sodium pyruvate, $10 \mathrm{mM} / 1$ HEPES) supplemented with $10 \% \mathrm{FBS}$, $100 \mathrm{U} / \mathrm{ml}$ penicillin and $100 \mu \mathrm{g} / \mathrm{ml}$ streptomycin at $37^{\circ} \mathrm{C}$ and 
in $5 \% \mathrm{CO}_{2}$. In studies involving serum-starvation, FBS was replaced with $0.1 \% \mathrm{BSA}$.

Pancreatic islets were isolated from male Sprague-Dawley rats (250-300 g) by $1 \mathrm{mg} / \mathrm{ml}$ collagenase $\mathrm{P}$ (Roche, Indianapolis, IN) digestion, separated by discontinuous Ficoll gradient purification (Biochrom AG, Berlin, Germany), and cultured free-floating in $10 \mathrm{ml}$ of Medium 199 (Gibco, Grand Island, NY). Individual islets were selected using micropipettes.

Preparation of non-viral vectors and plasmids. To evaluate the efficiency of non-viral vectors for gene delivery into rat islet cells, three different classes of transfection reagents were chosen, Effectene (Qiagen, Valencia, CA), PEI, and HVJ-E (Cosmo Bio Co., Tokyo, Japan). pEGFP-C1 (Clontech, Palo Alto, CA) and pCMV-Luc were used as reporter plasmids. These plasmids were introduced into E. coli strain JM109 (Promega) and purified using Qiagen Plasmid Maxi Kits (Qiagen).

For the transfection assays, INS-1 cells were seeded at a density of $5.0 \times 10^{5}$ cells/well in 12 -well plates. After $24 \mathrm{~h}$, cells were washed twice with serum-free OPTI-MEM media and then $2 \mathrm{ml}$ of fresh serum-free OPTI-MEM was added. Transfection conditions for Effectene/pCMV-Luc or HVJ-E/ pCMV-Luc were optimized according to the manufacturer's instructions. PEI 25K/pCMV-Luc complexes were prepared at a $5 / 1$ nitrogen of PEI $(\mathrm{N}) /$ phosphate of DNA $(\mathrm{P})$ ratio (12). The amount of plasmid was fixed at $2 \mu \mathrm{g} / \mathrm{well}$ and the complexes of plasmid and transfection reagent were added to each well. The cells were then incubated for $15 \mathrm{~h}$ at $37^{\circ} \mathrm{C}$ in a $5 \% \mathrm{CO}_{2}$ incubator. After the incubation, the transfection mixtures were removed and $2 \mathrm{ml}$ of fresh medium containing $10 \%$ FBS was added. INS-1 cells and rat islets were also transfected with $25 \mu 1$ Effectene/pEGFP-C1 complexes, or PEI $25 \mathrm{kDa} / \mathrm{pEGFP-C} 1$ complexes at 1,2 and $4 \mu \mathrm{g}$ DNA equivalents and incubated at $37^{\circ} \mathrm{C}$ for $>15 \mathrm{~h}$.

\section{Transfection efficiency}

Luciferase activity. After the incubation, INS-1 cells were washed with PBS twice, and $200 \mu 1$ of reporter lysis buffer (Promega, Madison, WI) was added to each dish. After $15 \mathrm{~min}$ of incubation at room temperature, cells were harvested and transferred to microcentrifuge tubes. After $15 \mathrm{sec}$ of vortex mixing, cells were centrifuged at 13,000 rpm for $3 \mathrm{~min}$. The extract was transferred to fresh tubes and stored at $-70^{\circ} \mathrm{C}$ until use. The protein concentration of the extract was determined by using a BCA protein assay kit (Thermo Scientific Pierce, Rockford, IL). Luciferase activity was measured in terms of relative light units (RLU) using a 96-well plate luminometer (Berthold Detection System GmbH, Pforzheim, Germany). The luciferase activity was monitored and integrated over a period of $20 \mathrm{sec}$. The final values of luciferase activity were reported in terms of RLU/mg total protein.

Measurement of GFP expression using flow cytometry and fluorescence microscope. Transfection efficiency was determined by flow cytometry using enhanced green fluorescent protein (EGFP). Briefly, the transfected cells were washed with PBS and harvested by trypsinization. Cells were recovered by centrifugation at $1,000 \mathrm{rpm}$ for $5 \mathrm{~min}$ at room temperature, and the pellet was resuspended in $1 \mathrm{ml}$ PBS. Transfection efficiency was quantified and expressed as percentage of
EGFP-expressing cells using a flow cytometer with Cell Quest software (Becton-Dickinson FACS Vantage, San Jose, CA). The transfection efficiency of rat islets was determined by counting the number of the fluorescent positive islets and total islets in the same microscopic field. A minimum of 50 islet cells was counted in quadruplicate in each experimental group.

\section{Measurement of cell viability}

Flow cytometry analysis. Viability after transfection was assessed using 7-amino actinomycin D (7-AAD, Sigma) to determine the percentage of dead cells by flow cytometry as described above.

Acridine orange/Propidium iodide fluorescent staining. Islet viability was also evaluated by fluorescent staining with acridine orange/propidium iodide (AO/PI) (Sigma, St. Louis, $\mathrm{MO})$. An AO/PI stock solution was prepared with $0.67 \mu \mathrm{M}$ $\mathrm{AO}$ and $75 \mu \mathrm{M}$ PI in PBS. Aliquots of the islets were mixed with $190 \mu \mathrm{l}$ of AO/PI stock solution. Islets fluorescing green were regarded as viable. Islets fluorescing orange, either fully or partially, were regarded as nonviable.

In vitro transfection and hypoxia-inducible vascular endothelial growth factor (VEGF) expression assay. The construction of pSV-VEGF and pRTP801-VEGF was described previously (13). Effectene was used as a gene carrier. Transfection conditions of Effectene/pSV-VEGF or pRTP-VEGF were optimized according to the manufacturer's instructions. The amount of plasmid was fixed at $1 \mathrm{mg} /$ well and the complexes were added to each well $(n=4)$. The rat islets were then incubated at $37^{\circ} \mathrm{C}$ in a $5 \% \mathrm{CO}_{2}$ incubator. After $4 \mathrm{~h}$, the transfection mixtures were removed and $100 \mu 1$ of fresh Medium 199 containing 10\% FBS was added. Cells were incubated at the desired concentration of oxygen (normoxia, 20\% oxygen; hypoxia, $1 \%$ oxygen) for $12 \mathrm{~h}$. ELISA was performed using a Biosource Human Vascular Endothelial Growth Factor ELISA kit (Biosource International Inc., Camarillo, CA) (14).

Statistical analysis. Statistical analysis was performed using the PRISM (GraphPad Software Inc, San Diego, CA). Results are expressed as means $\pm \mathrm{SD}$. The one-way analysis of variance (ANOVA) was used for comparisons involving more than two groups. Statistical significance was defined by convention as a $\mathrm{p}$-value $<0.05$.

\section{Results}

Transfection efficiency measurements. Transfection efficiencies were determined for three non-viral vectors using pCMV-Luc and pEGFP-C1, and rat INS-1 cells and rat islets.

Rat INS-1 cells. First, the transfection efficiency was assessed by luciferase activity. Effectene showed the highest transfection efficiency among the non-viral carriers. HVJ-E was the least effective transfection carrier. The efficiency of Effectene $\left(6.47 \times 10^{7} \pm 1.46 \times 10^{7} \mathrm{RLU} / \mathrm{mg}\right)$ was significantly higher than that of $25-\mathrm{kDa}$ PEI $\left(2.44 \times 10^{7} \pm 8.1 \times 10^{7} \mathrm{RLU} / \mathrm{mg}\right)$ and HVJ-E $\left(5.77 \times 10^{3} \pm 3.69 \times 10^{3} \mathrm{RLU} / \mathrm{mg}\right)(\mathrm{p}<0.001$ for both, Fig. 1a).

Second, the transfection efficiency was assessed by GFP expression. A negligible number of GFP positive cells were observed in the cells transfected with HVJ-E (Fig. 1b). In 
A.

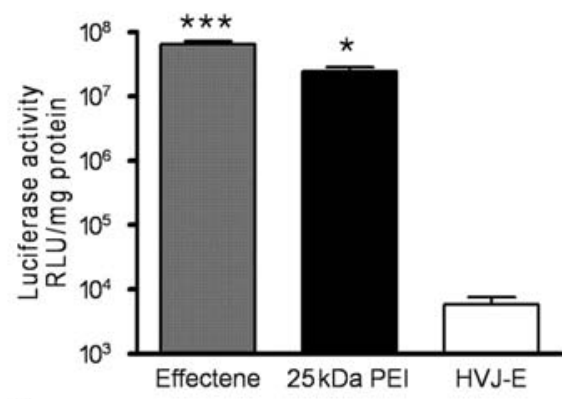

B.

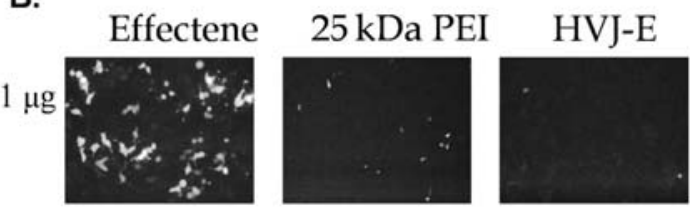

C.
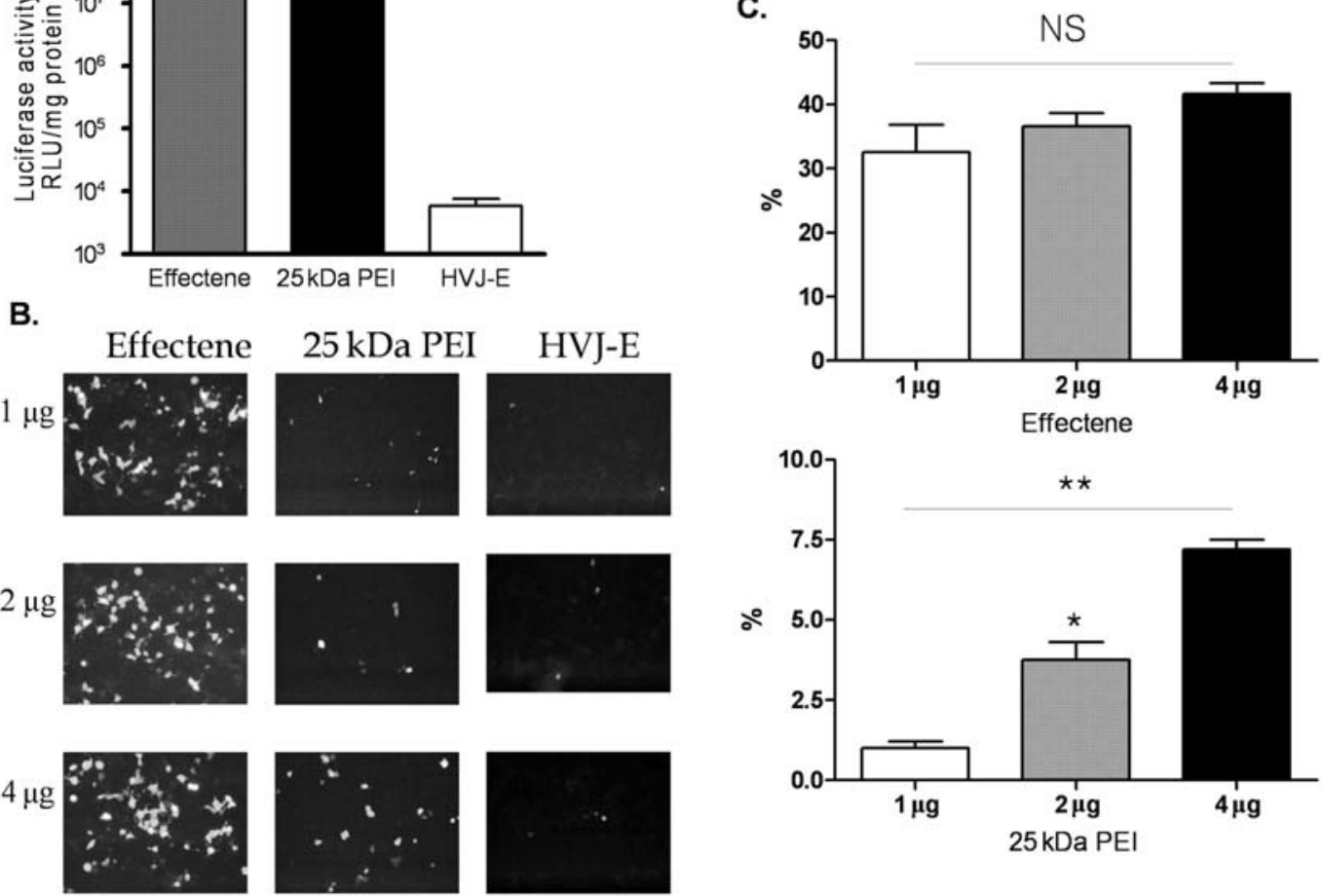

$25 \mathrm{kDa} P E \mathrm{P}$

Figure 1. Transfection efficiency of Effectene, PEI, or HVJ-E into INS-1 cells. (A) Transfection efficiency was assessed by the luciferase activity of pCMV-Luc delivered with Effectene, PEI, or HVJ-E. The efficiency of Effectene was significantly higher than that of PEI and HVJ-E ( ${ }^{* * *}$ p $<0.001$ for both). 25-kDa PEI was significantly more efficient than HVJ-E ( $\left.{ }^{*} \mathrm{p}<0.05\right)$. (B) Fluoresence microscopy and (C) flow cytometry. Transfection efficiency was also evaluated using fluorescence microscopy and flow cytometry in pEGFP-C1-transfected cells. Negligible numbers of GFP-positive cells were seen in the INS-1 cells transfected with HVJ-E. Effectene was significantly more effective $(\mathrm{p}<0.0001)$ for transgene expression than PEI $\left({ }^{*} \mathrm{p}<0.05,{ }^{* *} \mathrm{p}<0.01 \mathrm{vs} .1 \mu \mathrm{g}\right)$.

flow cytometric counting of GFP positive cells, Effectene was significantly more effective than PEI ( $\mathrm{p}<0.0001$ for Effectene vs. $25-\mathrm{kDa}$ PEI), with GFP expression ranging from 32.6 to $41.6 \%(32.6 \%$ in $1 \mu \mathrm{g}, 36.6 \%$ in $2 \mu \mathrm{g}$, and $41.6 \%$ in $4 \mu \mathrm{g}$, $\mathrm{p}=0.16)$. For PEI, expression ranged from 1.0 to $7.5 \%(1.0 \%$ in $1 \mu \mathrm{g}, 3.8 \%$ in $2 \mu \mathrm{g}$, and $7.5 \%$ in $4 \mu \mathrm{g}$ ). P-values for $1 \mu \mathrm{g}$ vs. 2 and $4 \mu \mathrm{g}$ were $<0.05$ and 0.01 , respectively. For $2 \mu \mathrm{g}$ vs. $4 \mu \mathrm{g}, \mathrm{p}<0.05$ (Fig. 1c).

Rat islets. Fig. 2 shows rat islets transfected with pEGF-C1 using Effectene, PEI, and HVJ-E. Compared with $25-\mathrm{kDa}$ PEI, the Effectene showed significantly higher transfection efficiency in rat islet cells ( $\mathrm{p}<0.001$, Effectene vs. PEI). The percentages of GFP-positive islets from 50 Effectenetransfected islets were $50.5 \pm 9.6,54.0 \pm 19.1$ and $61.0 \pm 17.5 \%$ for 1,2 , and $4 \mu \mathrm{g}$ DNA equivalents, respectively $(\mathrm{p}=0.65)$. The percentages of GFP-positive islets from 50 PEI-transfected islets were $25.3 \pm 4.8,27.0 \pm 9.6$ and $30.5 \pm 8.7 \%$ using 1 , 2 , and $4 \mu \mathrm{g}$ DNA equivalents, respectively $(\mathrm{p}=0.65)$.

Effects of transfection on cell viability. For the determination of cytotoxicity, composition and preparation of transfection complexes and conditions were the same as those used in the efficiency experiments.

Rat INS-1 cells. Flow cytometry for 7-AAD showed the cytotoxicity of Effectene (7.4-8.2\%) was similar to that of 25-kDa PEI (6.9-8.4\%, Fig. 3a).
Rat islets. AO/PI staining (Fig. 3b) showed that both Effectene/plasmid and PEI/plasmid complexes were minimally toxic to rat islets.

Hypoxic-inducible VEGF expression. Rat islets were transfected with pSV-VEGF and pRTP801-VEGF and incubated under normoxia or hypoxia conditions for $20 \mathrm{~h}$. In pSV-VEGF, VEGF expression was regulated by the SV40 promoter. In pRTP801-VEGF, VEGF expression was under the control of the RTP801 promoter, which is a hypoxia inducible promoter. The VEGF was significantly induced in the islets transfected with pRTP801-VEGF under hypoxia conditions (Fig. 4). This effect was not observed in the islets transfected with pSV40-VEGF, suggesting that the RTP801 promoter increased VEGF expression specifically in islets under hypoxia.

\section{Discussion}

Synthetic delivery systems have been investigated as an alternative to viral vectors because they raise fewer safety issues, are easier to produce, and pose fewer problems for repeated administration than viral gene transduction (15). The variability in transfection efficiencies for non-viral delivery systems in vitro and in vivo, especially in primary cells, might be dependent on transfected cell types, delivery system, size of the transfection system, or the ratio of DNA to reagent (16). 


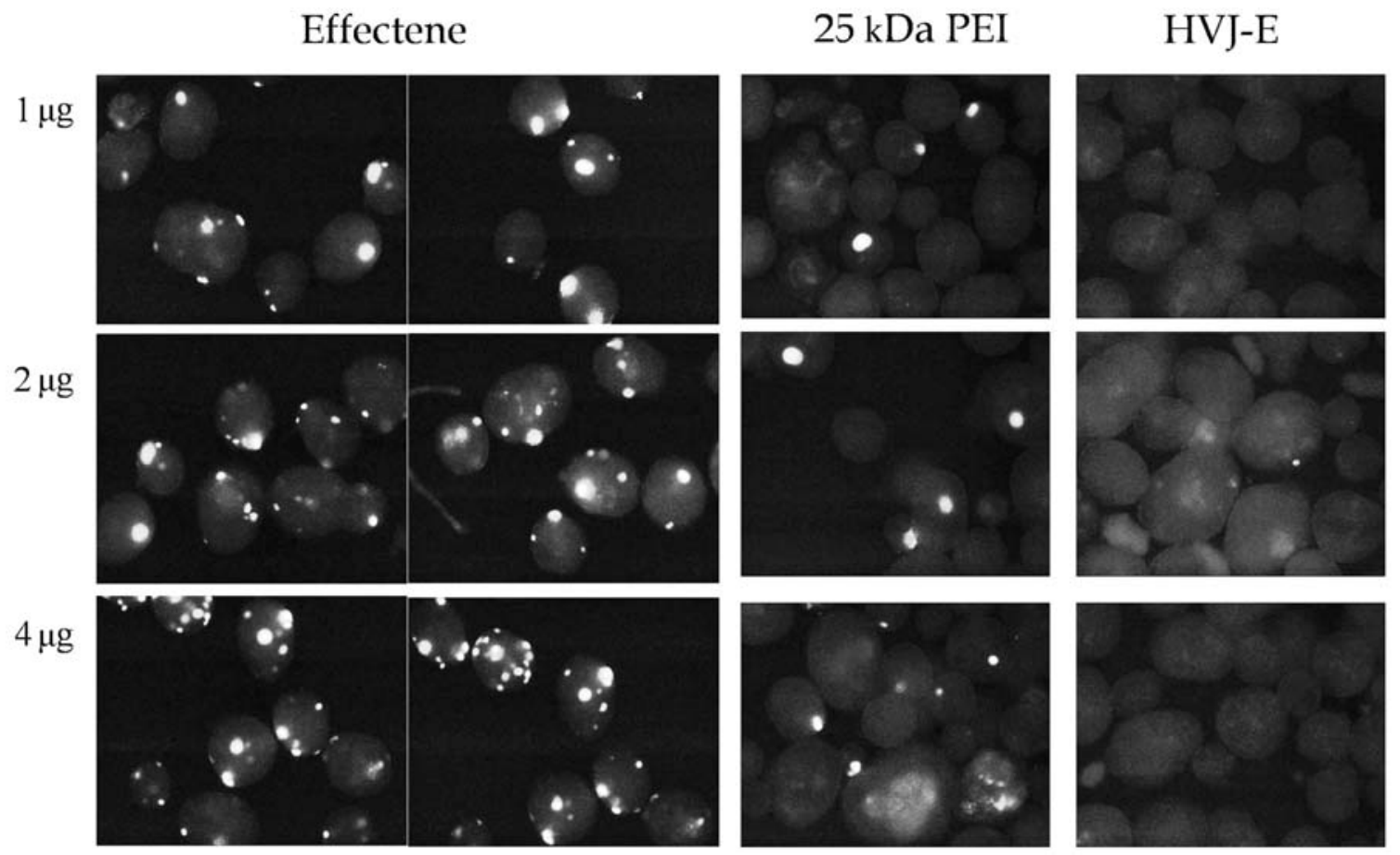

Figure 2. Transfection efficiency of Effectene, 25-kDa PEI and HVJ-E in rat islets assessed by GFP. Rat islets were transfected with pEGFP-C1 using Effectene, 25-kDa PEI and HVJ-E and GFP fluorescence was observed by microscopy. The Effectene showed significantly higher transfection efficiency in rat islet cells than 25-kDa PEI. A negligible number of GFP-positive cells were seen in the rat islet cells transfected with HVJ-E.

A.
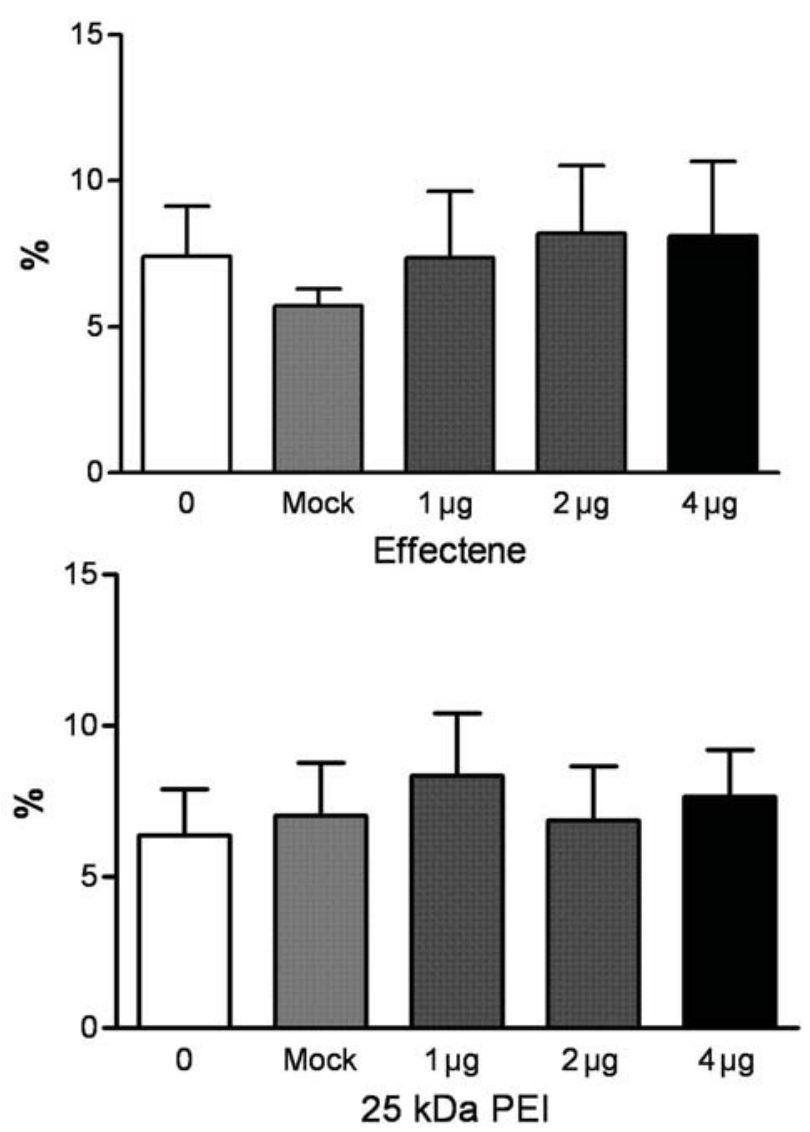

B.

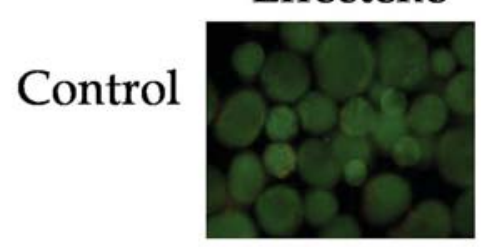

Mock

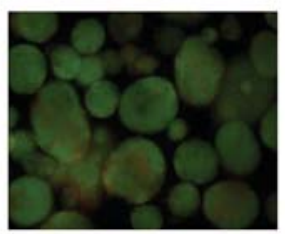

$1 \mu \mathrm{g}$

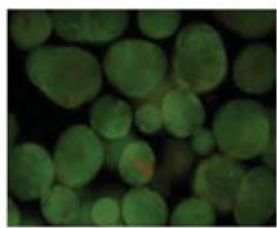

$2 \mu \mathrm{g}$

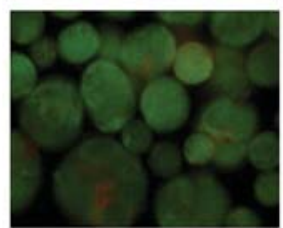

$4 \mu \mathrm{g}$

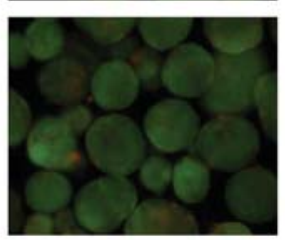

$25 \mathrm{kDa}$ PEI
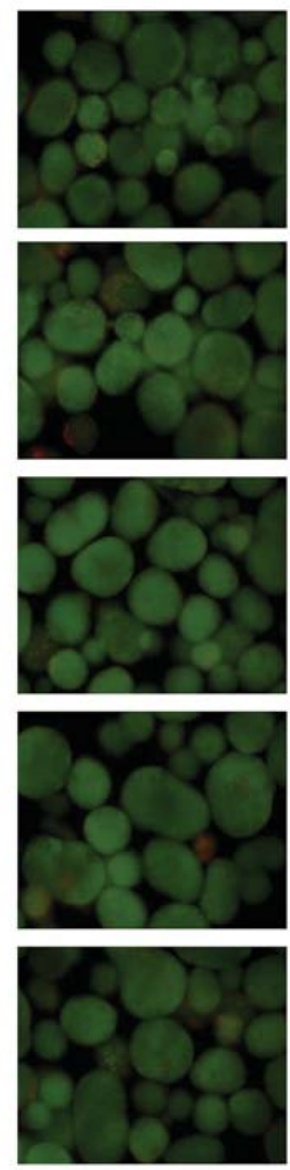

Figure 3. Transfection cytotoxicity in INS-1 cells and rat islets. (A) Flow cytometry for 7-AAD fluorescence showed the cytotoxicity of PEI ranging from 6.9 to $8.4 \%$ and Effectene ranging from 7.4 to $8.2 \%$. (B) Cytotoxicity in rat islets assessed by AO/PI showed that Effectene/plasmid and PEI/plasmid complexes were minimally toxic to rat islets. 


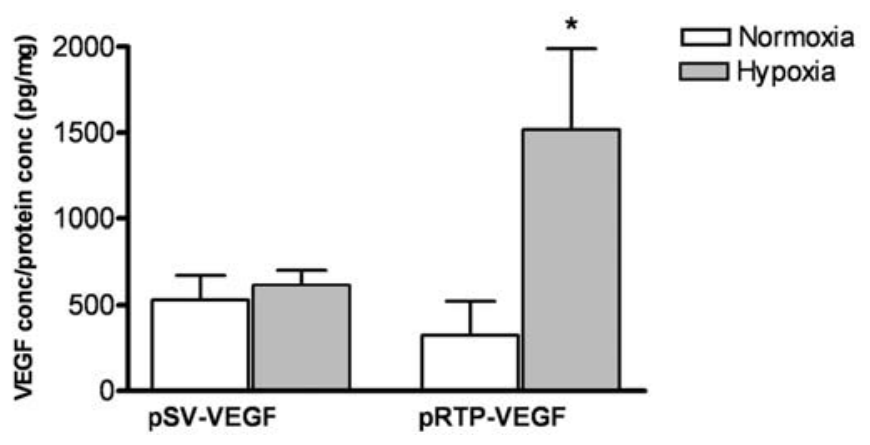

Figure 4. VEGF expression by pSV-VEGF or pRTP801-VEGF. pSV-VEGF/ Effectene or pRTP801-VEGF/Effectene complexes were transfected into rat islets. The islets were exposed to normoxia or hypoxia for $20 \mathrm{~h}$. The expression of VEGF was measured by ELISA. ${ }^{*} \mathrm{p}<0.05$ as compared with normoxia.

Transfection into pancreas islet cells is difficult because islets have an extracellular matrix (17) and are static, with a low proliferative rate (18). This is especially true in cultured pancreatic islets, which exist as spheroidal clusters of 1,0002,000 cells that are difficult to transfect by physical methods (19). Many other factors in the optimization of non-viral gene transfer are still poorly understood and require further investigation, especially with pancreatic islet cells. In this study, we performed a comparative analysis of the transfection efficiency and cytotoxicity of clinically applicable non-viral vectors that are candidates for islet gene therapy, and optimized transfection conditions into pancreatic islet cells.

PEI is a highly charged cationic organic polymer containing amino nitrogen at every third carbon. It is one of the most widely used non-viral gene carriers (20-22). The high transfection efficiency of PEI is due to the proton sponge effect, which facilitates endosomal escape of PEI/DNA complexes. PEI is also easily modified by conjugation to targeting moieties or other functional groups. PEI has different transfection efficiencies, depending on its molecular weight and the form of PEI. In this study, branched 25-kDa PEI was compared with other non-viral vectors for transfection into the pancreatic B-cells based on a previous report that the efficiency of $25 \mathrm{kDa}$ branched PEI was significantly higher than that of a PAMAM dendrimer or $2 \mathrm{kDa}$ linear PEI (14). Hemagglutinating virus of Japan envelope (HVJ-E, an inactivated Sendai virus envelope) was reported to be useful and efficient as a non-viral vector for gene delivery (23). HVJ-E incorporates a variety of molecules (DNA, RNA, proteins, and drugs) and delivers them into mammalian cells via membrane fusogenic activity. Although the HVJ-E vector was widely adopted as a gene transfection reagent in diverse cells, to our knowledge, there are no published reports of gene transfection into pancreatic islets. Effectene reagent is a synthetic cationic non-liposomal lipid formulation that is used in conjunction with a special DNA-condensing enhancer and an optimized buffer to achieve high transfection efficiencies (24). The enhancer first condenses the DNA molecules, and Effectene subsequently coats them with cationic lipids, providing a particularly efficient way of transferring DNA into eukaryotic cells. We previously demonstrated the superiority of non-liposomal lipid Effectene reagent over the liposomal lipid Lipofectamine for high- efficiency gene transfer into isolated pancreatic islets in culture (4). For these reasons, we used $25 \mathrm{kDa}$ branched-PEI, HVJ-E, and Effectene to represent different classes of non-viral gene delivery system in this study.

The efficiency of the PEI and Effectene vectors was dependent on the DNA/carrier ratio within the range of 1-4 $\mu \mathrm{g}$ DNA. In the range of 1-4 $\mu \mathrm{g}$ DNA of pEGFP-C1/Effectene or 25-kDa PEI, the DNA dose did not significantly affect the cytotoxicity. Our transfection results using dividing rat INS-1 cells and non-dividing rat pancreas islets showed that Effectene was more efficient than other non-viral vectors.

The viability of transplanted islets decreases with time, which is in part due to hypoxia after transplantation. Previously, it was shown that delivery of VEGF to islets using adenovirus or Effectene vector increased the survival of transplanted islets $(4,25)$. However, VEGF poses a safety problem for clinical applications, since it induces overgrowth of endothelial cells and hemangioma $(12,26)$. Therefore, regulation of VEGF gene expression is crucial for VEGF gene transfer. Using the secretory VEGF peptide, rat islets were transfected with pSV- and pRTP801-VEGF using Effectene reagent, and the transfected islets were incubated under normoxia or hypoxia conditions for $20 \mathrm{~h}$. VEGF was induced in the hypoxic islets transfected with pRTP801-VEGF. This effect was not observed in islets transfected with pSV40-VEGF, however, suggesting that the RTP801 promoter increased VEGF expression specifically in islets under hypoxia. This finding was in accordance with our previous report using PEI as a gene carrier (14)

Non-viral vectors are far less efficient than viral vectors for gene transfection into pancreatic islets. This is acceptable, however, depending on the target gene chosen. Overexpression of a therapeutic secretory peptide by a small portion of islet cells may be sufficient for some therapeutic aims of islet transplantation $(1,4)$. Our results provide useful information for optimizing transfer conditions using non-viral vectors in human islet transplantation trials. In summary, we investigated the prospects of non-viral vectors for gene delivery and demonstrated that Effectene formulations transfer genes with relatively high efficiency and low cytotoxicity to the pancreatic islets.

\section{Acknowledgements}

This work was supported by the Korea Research Foundation Grant funded by the Korean Government (MOEHRD, Basic Research Promotion Fund) (KRF-2008-331-E00038) and a grant from the Innovative Research Institute for Cell Therapy, Republic of Korea (A062260).

\section{References}

1. Davalli AM, Ogawa Y, Ricordi C, Scharp DW, Bonner-Weir S and Weir GC: A selective decrease in the beta cell mass of human islets transplanted into diabetic nude mice. Transplantation 59: 817-820, 1995

2. Van der Windt DJ, Bottino R, Casu A, Campanile $\mathrm{N}$ and Cooper DK: Rapid loss of intraportally transplanted islets: an overview of pathophysiology and preventive strategies. Xenotransplantation 14: 288-297, 2007.

3. Emamaullee JA and Shapiro AM: Factors influencing the loss of beta-cell mass in islet transplantation. Cell Transplant 16: 1-8, 2007. 
4. Chae HY, Lee BW, Oh SH, Ahn YR, Chung JH, Min YK, Lee MS, Lee MK and Kim KW: Effective glycemic control achieved by transplanting non-viral cationic liposome-mediated VEGF-transfected islets in streptozotocin-induced diabetic mice. Exp Mol Med 37: 513-523, 2005.

5. Narang AS and Mahato RI: Biological and biomaterial approaches for improved islet transplantation. Pharmacol Rev 58: 194-243, 2006.

6. Narang AS, Cheng K, Henry J, Zhang C, Sabek O, Fraga D, Kotb M, Gaber AO and Mahato RI: Vascular endothelial growth factor gene delivery for revascularization in transplanted human islets. Pharm Res 21: 15-25, 2004.

7. Li S and Huang L: Nonviral gene therapy: promises and challenges. Gene Ther 7: 31-34, 2007.

8. Luo D and Saltzman WM: Synthetic DNA delivery systems. Nat Biotechnol 18: 33-37, 2000.

9. Nishikawa M and Huang L: Nonviral vectors in the new millennium: delivery barriers in gene transfer. Gene Ther 12: 861-870, 2001

10. Mahato RI, Henry J, Narang AS, Sabek O, Fraga D, Kotb M and Gaber AO: Cationic lipid and polymer-based gene delivery to human pancreatic islets. Mol Ther 7: 89-100, 2003.

11. Benhamou PY, Moriscot C, Prevost P, Rolland E, Halimi S and Chroboczek J: Standardization of procedure for efficient ex vivo gene transfer into porcine pancreatic islets with cationic liposomes. Transplantation 63: 1798-1803, 1997.

12. Lee M, Rentz J, Han SO, Bull DA and Kim SW: Water-soluble lipopolymer as an efficient carrier for gene delivery to myocardium. Gene Ther 10: 585-593, 2003.

13. Lee M, Bikram M, Oh S, Bull DA and Kim SW: Sp1-dependent regulation of the RTP801 promoter and its application to hypoxia-inducible VEGF plasmid for ischemic disease. Pharm Res 21: 736-741, 2004.

14. Kim HA, Lee BW, Kang DC, Kim JH, Ihm SH and Lee M: Delivery of hypoxia inducible VEGF gene to rat islets using polyethylenimine. J Drug Target 17: 1-9, 2009.

15. Kiefer K, Clement J, Garidel P and Peschka-Süss P: Transfection efficiency and cytotoxicity of nonviral gene transfer reagents in human smooth muscle and endothelial cells. Pharm Res 21: 1009-1017, 2004.

16. Da Cruz MT, Simões S, Pires PP, Nir S and De Lima MC: Kinetic analysis of the initial steps involved in lipoplex-cell interactions: effect of various factors that influence transfection activity. Biochim Biophys Acta 1510: 136-151, 2001.
17. Lee DY, Park SJ, Nam JH and Byun Y: Optimal aggregation of dissociated islet cells for functional islet-like cluster. J Biomater Sci Polym Ed 19: 441-452, 2008.

18. Friedrichsen BN, Neubauer N, Lee YC, Gram VK, Blume N, Petersen JS, Nielsen JH and Møldrup A: Stimulation of pancreatic beta-cell replication by incretins involves transcriptional induction of cyclin D1 via multiple signalling pathways. J Endocrinol 188: 481-492, 2006

19. Bain JR, Schisler JC, Takeuchi K, Newgard CB and Becker TC: An adenovirus vector for efficient RNA interference-mediated suppression of target genes in insulinoma cells and pancreatic islets of langerhans. Diabetes 53: 2190-2194, 2004.

20. Lee M, Choi D, Choi MJ, Jeong JH, Kim WJ, Oh S, Kim YH, Bull DA and Kim SW: Hypoxia-inducible gene expression system using the erythropoietin enhancer and 3'-untranslated region for the VEGF gene therapy. J Control Release 115: 113119,2006

21. Zhang C, Yadava P and Hughes J: Polyethylenimine strategies for plasmid delivery to brain-derived cells. Methods 33: 144-150, 2004.

22. Durocher Y, Perret S and Kamen A: High-level and highthroughput recombinant protein production by transient transfection of suspension-growing human 293-EBNA1 cells. Nucleic Acids Res 30: E9, 2002.

23. Kaneda Y, Yamamoto S and Nakajima T: Development of HVJ envelope vector and its application to gene therapy. Adv Genet 53: 307-332, 2005

24. Young AT, Lakey JR, Murray AG and Moore RB: Gene therapy: a lipofection approach for gene transfer into primary endothelial cells. Cell Transplant 11: 573-582, 2002.

25. Zhang N, Richter A, Suriawinata J, Harbaran S, Altomonte J, Cong L, Zhang H, Song K, Meseck M, Bromberg J and Dong H: Elevated vascular endothelial growth factor production in islets improves islet graft vascularization. Diabetes 53: 963-970, 2004.

26. Su H, Arakawa-Hoyt J and Kan YW: Adeno-associated viral vector-mediated hypoxia response element-regulated gene expression in mouse ischemic heart model. Proc Natl Acad Sci USA 99: 9480-9485, 2002. 